\title{
The Perception of Stakeholders to Implement Nature- Based Solution for Flood Protection in the Balkans and in Iceland ${ }^{+}$
}

\author{
David C. Finger 1,* Aleksa Lipovac ${ }^{2}$, Ruzica Stricevic ${ }^{2}$, Aleksandra Figurek ${ }^{3}$, \\ Marijana Kapovic-Solomun ${ }^{3}$ and Vesna Zupanc ${ }^{4}$ \\ 1 Sustainability Institute and Forum (SIF), School of Science and Engineering, Reykjavik University, \\ 101 Reykjavík, Iceland; davidf@ru.is \\ 2 Faculty of Agriculture, University of Belgrade, 11000 Belgrade, Serbia; aleksalipovac@gmail.com (A.L.); \\ sruzica@agrif.bg.ac.rs (R.S.) \\ 3 Faculty of Agriculture, University of Banja Luka, 78000 Banja Luka, Bosnia and Herzegovina; \\ aleksandra.figurek@agro.unibl.org (A.F.); marijana.kapovic-solomun@sf.unibl.org (M.K.-S.) \\ 4 Biotechnical Faculty, University of Ljubljana, 1000 Ljubljana, Slovenia; Vesna.Zupanc@bf.uni-lj.si \\ * Correspondence: davidf@ru.is \\ † Presented at TERRAenVISION 2019, Barcelona, Spain, 2-7 September 2019.
}

Published: 26 December 2019

\begin{abstract}
Recent climate change observations and projections reveal an intensification of weather patterns, leading to severe floods and droughts in most parts of the world. The intensification of weather patterns could mitigate the effectiveness of flood protection infrastructures such as dams, levees and flood channels. Numerous studies have highlighted the superior effect of Nature-Based Solutions (NBS) in order to manage and mitigate the hydro-meteorological risk generated by an intensified water cycle. In particular, Natural Water Retention Measures (NWRM) can prove to be efficient, sustainable and flexible solutions. NWRMs reduce flood events, mitigate flood damage and provide biological habitats for the conservation of local flora and fauna. Accordingly, NWRM should be implemented on a large scale throughout the river basins with the close involvement of local stakeholders and landowners. For this purpose, we assessed the perception of stakeholders and landowners of applying NWRM on private properties in four European countries (Iceland, Serbia, Bosnia-Herzegovina, and Slovenia). Country-specific semi-quantitative questionnaires were created for representative watersheds in all four countries. The questionnaires took into account that floods are characterized by the country-specific precipitation, topography of the terrain and the nature of the watercourse. Therefore different NWRMs were recommended between the countries. Based on the preliminary analysis, we have concluded similar outcomes for all four states: Landowners want to cooperate with local communities and governments in order to adopt flood protection measures. They pointed to NWRM as equally important as an engineering-based solution, but they are not particularly willing to implement NWRM on their private lands. Landowners indicate that the government should have at least a $75 \%$ share in financing flood protection measures. The similarities of the results in the four countries reveal that a Pan-European perception might be generated by conducting similar surveys in other European countries.
\end{abstract}

Keywords: nature-based solutions; flood; drought; land management; stakeholder

(C) 2019 by the authors. Licensee MDPI, Basel, Switzerland. This article is an open access article distributed under the terms and conditions of the Creative Commons Attribution (CC BY) license (http://creativecommons.org/licenses/by/4.0/). 